\title{
Examination of the Relationship between Mood and Achievement Goal Orientations of the Students Studying at Faculty of Sports Sciences
}

\author{
Barbaros Serdar Erdogan ${ }^{1}$ \\ Nazmi Baykose ${ }^{2}$ iD
}

'Faculty of Sport Sciences, Mehmet Akif Ersoy University, Burdur, Turkey. Email:bserdogan@mehmetakif.edu.tr

"Faculty of Sport Sciences, Akdeniz University, Antalya, Turkey.

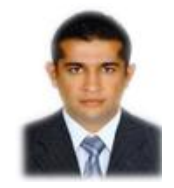

(Corresponding Author

\section{Abstract}

The aim of this study is to examine the relationship between affect and achievement-goal orientations of sports science faculty students. Participants forming the research group are studying at the faculty of sports sciences at Mehmet Akif Ersoy University, and in terms of gender, the research group consists of a total of 487 students, 272 males and 215 females ( $\bar{x}_{\text {age }}=23.08+3.271$ ). The first of the measurement tools used in line with the research purpose; It is the Achievement Goal Orientations Scale, which was developed by Midgley et al. (1998) and gained literature by adaptation to Turkish culture by Akın (2006) Secondly, the Positive and Negative Affectivity Scale, which was originally developed by Watson, Clarck, and Tellegen (1988) under the name of "Positive and Negative Affectivity Schedule" and adapted to Turkish culture by Gençöz (2000) was used. Pearson Correlation test, Anova test and independent samples t test were used in the solution and interpretation of the data. As a result, it was observed that there was a relationship between the achievement-goal orientations of the sports faculty students and their mood (positive and negative).

Keywords: Mood, Goal orientations, Student, Sports, Sport science, Achievement goal.

Citation | Barbaros Serdar Erdogan; Nazmi Baykose (2021). Examination of the Relationship between Mood and Achievement Goal Orientations of the Students Studying at Faculty of Sports Sciences. Asian Journal of Education and Training, 7(1): 46-50. History:

Received: 20 November 2020

Revised: 22 December 2020

Accepted: 7 January 2021

Published: 25 January 2021

Licensed: This work is licensed under a Creative Commons Attribution 3.0 License $(\mathrm{cc})$

Publisher: Asian Online Journal Publishing Group
Acknowledgement: Both authors contributed to the conception and design of the study.

Funding: This study received no specific financial support

Competing Interests: The authors declare that they have no conflict of interests.

Transparency: The authors confirm that the manuscript is an honest, accurate, and transparent account of the study was reported; that no vital features of the study have been omitted; and that any discrepancies from the study as planned have been explained.

Ethical: This study follows all ethical practices during writing.

\section{Contents}

1. Introduction ......................... 47

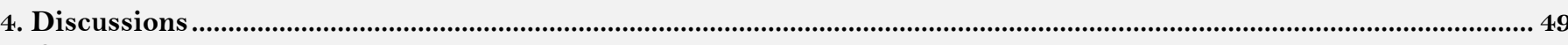

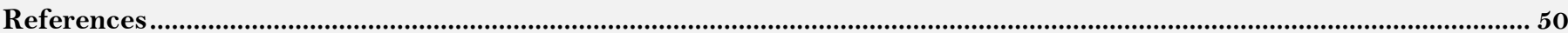




\section{Contribution of this paper to the literature}

This study contributes to existing literature by examining the relationship between affect and achievement-goal orientations of sports science faculty students.

\section{Introduction}

It is a well-known fact that technology developing in the 21 st century facilitates access to information. In addition to the objectively relation between access to information and technological development, attempts continue to determine educational environments and the needs of students, who are the main subjects of the education system. It is possible for students to obtain information not only in the classroom but also through the internet, which is an advantage of the developing age. Of course, the most prominent feature that emerges at this point is the willingness of students to learn. Taking advantage of the 21 st century is shaped in parallel with individuals' willingness and motivation to learn. In the age we live in, this willingness and motivation is one of the most basic elements that will guide the lives of students. Moods are at the top of the elements that direct people's lives. If we need to classify these feelings of people, these feelings can be divided into two opposite categories as positive and negative moods. It is also possible that this distinction can be divided into useful or unhelpful from a utilitarian point of view. In this case, the emotion classification commonly used in the relevant literature is positive and negative mood (Weiss \& Cropanzano, 1996).

While it can be said that a positive mood (affection) leaves a good and pleasant impression on the individual, it would not be wrong to say that a negative moods (affection) leaves a bad and unpleasant impression. For example happiness, hope, frugal passion, etc. While concepts are included in the positive mood classification, worry, anger, hate, etc. Concepts are included in the negative mood classification. As stated by Yalnız (2014) if an individual's level of positive mood is low, he may have a hopeless, pessimistic view of life as well as not being able to enjoy his life. In the relevant literature, it is known that positive and negative mood are associated with many concepts that are thought to be related (Karairmak \& Siviş-Çetinkaya, 2011). In the study conducted by Martin-Krumm, Sarrazin, Peterson, and Famose (2003) it can be said that athletes with high levels of optimism are less stressed, anxious, or having a high level of self-confidence provides a more successful performance indicator than athletes with high levels of pessimism.

Positive mood is among the factors that have an effective role on thought and behavior. The increase in positive mood has a positive effect on the to cope with stressful situations, as well as the skill to recover psychologically after a stressful situation. At the same time, it is known that positive mood has an effect on motivation (Fredrickson, 2001). Learning and teaching processes, achievement goals and learning process results are among the related concepts of positive mood in the relevant literature in terms of motivation (Menderes, 2009).

The subject of what motivates students, who are the main subjects of educational environments, is perhaps one of the most fundamental questions from the past to the present. If the students have a successful learning process, increase their current level of success and gain pedagogical knowledge, they will be better prepared for the future. The results of the research conducted in the relevant literature in the context of motivation for success show that there is not only one answer to this question (Weiner, 1990; Zweig \& Webster, 2004). Accordingly, it is stated that the main thing that should be emphasized regarding achievement-goal orientations is 'individuals' adaptation and adoption"(Pintrich, 2000).

In this context, the aim of this study is to examine the relationship between the mood of sports sciences students and their achievement-goal orientations.

\section{Method}

\subsection{Participants}

Participants forming the research group are studying at Mehmet Akif Ersoy University's faculty of sports sciences and in terms of gender, the research group consists of a total of 487 students, 272 males and 215 females $($ age $=23.08+3.271)$.

\subsection{Data Collection Tools}

\subsubsection{Demographic Information form}

The variables for research purposes were included in the demographic information form created by the researchers. These variables are age, gender, class variables.

\subsubsection{Positive and Negative Affect Schedule}

The Positive and Negative Affect Schedule (PANAS), originally developed by Watson et al. (1988), was used in order to measure the positive and negative mood of the individuals participating in the study. The scale is a 7-point Likert scale and consists of 20 items in total. While 10 of these 20 items are used to measure positive affect, the other 10 are used to measure negative affect. As can be understood from this information, the scale is structurally a two-sub-dimension scale. The sample of university students was used both in the development of the scale and in its adaptation to Turkish culture. While the internal consistency coefficient of the original scale was .88 for the positive affect sub-dimension, it was calculated as .87 for the negative affect sub-dimension. In addition, it has been reported that there is a negative relationship between scale sub-dimensions (Watson et al., 1988). While the internal consistency coefficient of the positive affect sub-dimension of the Turkish version of the scale, which was adapted to Turkish culture by Gençöz (2000), was .83, the internal consistency coefficient of the negative affect sub-dimension was calculated and reported as .86.

\subsubsection{Achievement Goal Orientation Scale}

Developed as three sub-dimensions by Midgley et al. (1998) to measure individuals' achievement-goal orientation / orientation, the measurement tool measures in attitudinal and behavioral contexts. The scale, whose validity and reliability was tested by Akın (2006) within the scope of adaptation study on the Turkish population, 
consists of 18 items. Learning goal orientation, the first of the three basic sub-dimensions, focuses on the developmental level of the individual, while the second sub-dimension, performance approach, focuses on individual development by prioritizing the satisfaction of other individuals. The last sub-dimension focuses on the feeling of being talented in society. In the original study in which the scale was developed, it was stated that the internal consistency coefficients for the reliability of the scale were between .62 and .84, and the reliability results on the Turkish population were reported to vary between .77 and .79 .

\subsection{Data Analysis}

Pearson Correlation test, Anova test and independent samples $t$ test were used in the solution and interpretation of the data. Within the scope of the study, the significance level was interpreted as $\mathrm{P}<0.05$ and $\mathrm{P}$ $<0.01$. SPSS (Statistical package for social sciences) package program was used for the evaluation and calculation of the data.

\section{Results}

Table-1. Comparison of variables according to the gender variable.

\begin{tabular}{|c|c|c|c|c|c|c|}
\hline & & $\mathbf{n}$ & $\bar{x}$ & S.d & $\mathbf{t}$ & $\mathbf{p}$ \\
\hline \multirow{2}{*}{ Positive Affect } & $\mathrm{W}$ & 215 & 31,38 & 7,01 & \multirow{2}{*}{$-1,567$} & \multirow{2}{*}{0,119} \\
\hline & $\mathrm{M}$ & 272 & 32,86 & 7,03 & & \\
\hline \multirow{2}{*}{ Negative Affect } & $\mathrm{W}$ & 215 & 26,64 & 6,93 & \multirow{2}{*}{$-0,750$} & \multirow{2}{*}{0,454} \\
\hline & $\mathrm{M}$ & 272 & 27,34 & 6,90 & & \\
\hline \multirow{2}{*}{ Objective Orientation } & $\mathrm{W}$ & 215 & 19,67 & 5,46 & \multirow{2}{*}{$-1,771$} & \multirow{2}{*}{0,078} \\
\hline & $\mathrm{M}$ & 272 & 20,94 & 5,23 & & \\
\hline \multirow{2}{*}{ Performance-approach goals } & $\mathrm{W}$ & 215 & 19,46 & 5,35 & \multirow{2}{*}{0,196} & \multirow{2}{*}{0,845} \\
\hline & $\mathrm{M}$ & 272 & 19,32 & 5,55 & & \\
\hline \multirow{2}{*}{ Performance-avoidance goals } & $\mathrm{W}$ & 215 & 13,81 & 4,70 & \multirow{2}{*}{$-0,867$} & \multirow{2}{*}{0,387} \\
\hline & $\mathrm{M}$ & 272 & 14,38 & 5,18 & & \\
\hline
\end{tabular}

When Table 1 is examined, it is seen that the sub-dimensions of achievement-goal orientation and positivenegative affect mean scores are seen. According to the gender variable, no significant difference was found in the means of the sub-dimensions of achievement-goal orientation and the averages of the mood sub-dimensions.

Table-2. Comparison of variables according to the class variable.

\begin{tabular}{|c|c|c|c|c|c|c|c|}
\hline & & S.S & df & M.S & $\mathbf{F}$ & p & Turkey \\
\hline \multirow{3}{*}{ Objective Orientation } & Between Groups & 1200,755 & 3 & 400,252 & \multirow{3}{*}{16,975} & \multirow{3}{*}{,000 } & $1-4$ \\
\hline & \begin{tabular}{|l} 
Within Groups \\
\end{tabular} & 5210,827 & 221 & 23,578 & & & $2-4$ \\
\hline & Total & 6411,582 & 224 & & & & $3-4$ \\
\hline \multirow{3}{*}{ Performance-approach goals } & Between Groups & 345,166 & 3 & 115,055 & \multirow{3}{*}{4,043} & \multirow{3}{*}{,008 } & $1-4$ \\
\hline & \begin{tabular}{|l} 
Within Groups \\
\end{tabular} & 6345,486 & 223 & 28,455 & & & $2-4$ \\
\hline & Total & 6690,652 & 226 & & & & $3-4$ \\
\hline \multirow{3}{*}{ Performance-avoidance goals } & Between Groups & 357,799 & 3 & 119,266 & \multirow{3}{*}{5,055} & \multirow{3}{*}{,002 } & $1-4$ \\
\hline & Within Groups & 5261,170 & 223 & 23,593 & & & $2-4$ \\
\hline & Total & 5618,969 & 226 & & & & $3-4$ \\
\hline
\end{tabular}

Note: * 1: Class 1, 2: 2 Class 3: 3rd Class, 4: 4th Class.

When Table 2 was examined, it was observed that there was a statistically significant difference between the mean scores of the goal orientation sub-dimension, one of the sub-dimensions of the achievement-goal orientations scale, in terms of class variable $(\mathrm{p}<0.05)$. When this observed difference is examined, 4th class students (mean: 16.10). It was observed that the mean scores were significantly lower than the students in the lower classs (1st Class: 21.29, 2. Class: 21.59, 3. Class: 22.04).

When Table 2 was examined, it was observed that there was a statistically significant difference between the mean scores of the sub-dimensions of the achievement-goal orientations scale in terms of class variable $(p<0.05)$. When this observed difference is examined, 4th class students (mean: 17.16). It was observed that the mean scores were significantly lower than the students in the lower classes (1st Class: 20.06, 2nd Class: 20.39, 3. Class: 19.50).

When Table 2 was examined, it was observed that there was a statistically significant difference between the mean scores of the sub-dimensions of the achievement-goal orientations scale in terms of the class variable ( $p$ $<0.05$ ). When this observed difference is examined, 4th class students (mean: 18.11). It was observed that the mean scores were significantly lower than the students in the lower classes (1st Class: 21.04, 2nd Class: 21.45, 3. Class: 22.30).

Table-3. Comparison of variables according to the class variable.

\begin{tabular}{|c|c|c|c|c|c|c|c|}
\hline & & $\mathbf{S . S}$ & df & M.S & $\mathbf{F}$ & p & Turkey \\
\hline \multirow{3}{*}{ Positive Affect } & Between Groups & 1160,732 & 3 & 386,911 & \multirow{3}{*}{8,600} & \multirow{3}{*}{, OOO } & $1-4$ \\
\hline & Within Groups & 9988,188 & 222 & 44,992 & & & $2-4$ \\
\hline & Total & 11148,920 & 225 & & & & $3-4$ \\
\hline \multirow{3}{*}{ Negative Affect } & Between Groups & 448,407 & 3 & 149,469 & \multirow{3}{*}{3,240} & \multirow{3}{*}{,023 } & $3-1$ \\
\hline & Within Groups & 10241,434 & 222 & 46,133 & & & $3-2$ \\
\hline & Total & 10689,841 & 225 & & & & $3-4$ \\
\hline
\end{tabular}

Note: * 1: Class 1, 2: 2 Class 3: 3rd Class, 4: 4th Class.

When Table 3 was examined, it was observed that there was a statistically significant difference between the mean scores of the positive affect sub-dimension, which is one of the sub-dimensions of the positive-negative affect 
Schedule, in terms of the class variable $(\mathrm{p}<0.05)$. When this observed difference is examined, 4 th class students (mean: 29.20). It was observed that the mean scores were significantly lower than the students in the lower classes (1st Class: 32.64, 2nd Class: 31.24, 3. Class: 35.55).

When Table 3 was examined, it was observed that there was a statistically significant difference between the mean scores of the negative affect sub-dimension, one of the sub-dimensions of the positive-negative affect Schedule, in terms of the class variable $(\mathrm{p}<0.05)$. When this observed difference is examined, the mean score of 3rd class students (mean: 24.7857) is significantly lower than the students in other classs (1st Class: 27.64, 2nd Class: 27.13, 4th Class: 28.73) It has been observed.

\begin{tabular}{l|c|c|c|c}
\hline \multicolumn{2}{c}{ Table-4. Correlation between positive and negative affect and goal orientation sub-dimensions. } \\
\hline \multirow{3}{*}{ Performance-approach goals } & $\mathrm{r}$ & $\begin{array}{c}\text { Objective } \\
\text { Orientation }\end{array}$ & $\begin{array}{c}\text { Performance-approach } \\
\text { goals }\end{array}$ & $\begin{array}{c}\text { Performance- } \\
\text { avoidance goals }\end{array}$ \\
\cline { 2 - 5 } & $\mathrm{p}$ &, $388^{* *}$ & \\
\cline { 2 - 5 } & $\mathrm{n}$ & 224 & & \\
\hline \multirow{3}{*}{ Performance-avoidance goals } & $\mathrm{r}$ &,$- 208^{* *}$ &, $235^{* *}$ & \\
\cline { 2 - 5 } & $\mathrm{p}$ &, 002 &, 000 & \\
\cline { 2 - 5 } & $\mathrm{n}$ & 224 & 224 &, $0187^{*}$ \\
\hline \multirow{3}{*}{ Positive Affect } & $\mathrm{r}$ &, $461^{* *}$ &, $234^{* *}$ & 224 \\
\cline { 2 - 5 } & $\mathrm{p}$ &, 000 &, 000 &, $386^{* *}$ \\
\cline { 2 - 5 } & $\mathrm{n}$ & 224 & 224 &, 000 \\
\hline
\end{tabular}

When we examine Table 4, we see a positive correlation between positive affect and achievement goal orientation sub-dimensions, learning goal orientation $(\mathrm{r}=0.461)$ and performance approach $(\mathrm{r}=0.234)$, and a negative correlation between performance avoidance $(r=-0.157)$. There is a negative correlation between negative affect and learning goal orientation $(\mathrm{r}=-0.194)$ and performance approach $(\mathrm{r}=-0.041)$ sub-dimensions, and a positive correlation between performance avoidance $(r=0.386)$. In addition, a correlation is observed between learning goal orientation sub-dimensions.

\section{Discussions}

According to the gender variable, no significant difference was found in the sub-dimensions of positive and negative moods and achievement-goal orientation. We can say that the mood of university students and their achievement-goal orientations do not vary according to gender. When the relevant literature is examined, Roebken (2007) advocating that there is no significant difference in terms of achievement-goal orientation in terms of gender variable in his study with university students supports our study. In another study conducted by Lin (1997) with a sample of 240 students, it examined whether the students' achievement-goal orientations changed according to their gender and could not find any difference between genders. Menderes (2009) also supports our study by stating that there is no significant difference in the sub-dimensions of achievement-goal orientation according to the gender variable. Some studies have found that there is a significant difference according to the gender variable, contrary to our study. Roeser, Midgley, and Urdan (1996) stated that male students are more prone to be performance oriented than girls. Ablard and Lipschultz (1998) stated that female students are more likely to adopt learning goals. Therefore, we can say that there is a difference in achievement goal orientation according to the gender variable.

In terms of class variable, it was observed that there was a statistically significant difference between the mean scores of the sub-dimensions of achievement-goal orientations scale, goal, performance approach and performanceavoidance orientation sub-dimensions. It can be said that 4th class students have lower mean scores than other class students in all of these sub-dimensions. When the studies in the literature regarding the change of achievement-goal orientations preferred by students according to the class level are examined, it is seen that some studies contradict our research findings.

However, it is clear that studies based on longitudinal research designs are needed to make clearer comments on this issue. As reported by Toğluk (2009) regarding the change in the students' preferred achievement-goal orientations according to the class level, the achievement-goal orientations of the students participating in the study were examined in terms of the class variable and it was stated that there was no statistical difference. There are studies in the relevant literature that support the findings we obtained as a result of our research (Eryenen, 2008; Küçükoğlu, Kaya, \& Turan, 2010; Menderes, 2009). Of course, apart from the descriptive findings of this research, a longitudinal research design on this subject is thought to make it possible for us to make a clearer explanation on this subject.

In terms of the class variable, a statistical difference was observed between the mean scores of the positive and negative affect sub-dimensions of the positive negative affect scale. When this observed difference was examined, it was observed that the mean scores of 4 th class students were significantly lower than those of lower classs. At the same time, when the level of negative affect is examined, it can be said that 3rd class students have a lower average score than other class.

In our study, it was determined that there is a correlation between the sub-dimensions of achievement-goal orientation and positive and negative moods. When we examine the results, there is a positive correlation between positive affect and achievement-goal orientation sub-dimensions, learning goal orientation and performance approach, while a negative correlation is observed between the performance avoidance sub-dimension.

In negative affect, on the contrary, there is a negative correlation between learning goal orientation and performance approach sub-dimension, and a positive correlation between performance avoidance sub-dimension. 
We can say that students with high positive affect adopt learning goal orientation and performance approach and are challenging, students with high negative affect adopt performance avoidance and avoid learning and performance approach and do not adopt struggle. When the relevant literature is examined, Bartels (2007) supports our study by arguing that while the performance-avoidance orientation from the success-goal orientations changes according to the negative affect, the performance-approach orientation changes according to the positive affect. In the study conducted by Menderes (2009) with 506 university students, it supports our study by finding that there is a positive relationship with positive affect and learning goal orientation and performance approach sub-dimension and that there is a positive relationship with negative affect and performance avoidance subdimension.

Another result we obtained in our study is the correlation between success-goal orientation sub-dimensions. When we look at the results, it is seen that there is a negative correlation between the performance avoidance subdimension and the learning goal orientation, and a positive correlation between the performance approach subdimension and the learning goal orientation. Akın (2006) supports our study by finding a negative correlation between the performance avoidance sub-dimension and the learning goal orientation sub-dimension, and a positive correlation between the performance approach and learning goal orientation in his study.

\section{References}

Ablard, K., \& Lipschultz, R. (1998). Self-regulated learning in high-achieving students: Relations to advanced reasoning, achievement goals, and gender. Journal of Educational Psychology, 9O(1), 94-101.Available at: https://doi.org/10.1037/0022-0663.90.1.94.

Akın, A. (2006). Relationships between achievement goal orientations and metacognitive awareness, parental attitudes and academic achievement. Sakarya: Sakarya University Institute of Social Sciences.

Bartels, J. M. (2007). Dispositional positive and negative affect and approach- avoidance achievement motivation. Individual Differences Research, 5(3), 246-259.

Eryenen, G. (2008). Pre-service teachers' goal orientations, relationships between academic and teaching self-efficacy and the role of these variables in predicting academic achievement. Unpublished Master's Thesis. Istanbul University, Institute of Social Sciences, Istanbul.

Fredrickson, B. (2001). The role of positive emotions in positive psychology. American Psychologist, 56(3), 218-226.Available at: https://doi.org/10.1037/0003-066x.56.3.218.

Gençöz, T. (2000). Positive and negative affect scale: Validity and reliability study. Turkish Journal of Psychology, 15(40), 19-26.

Karairmak, Ö., \& Siviş-Çetinkaya, R. (2011). The effect of self-esteem and locus of control on psychological resilience: The mediating role of emotions. Turkish Psychological Counseling and Guidance Journal, 4(35), 30-41.

Küçükoğlu, A., Kaya, İ., \& Turan, A. (2010). Examining the perceptions of achievement orientation of students in primary school teaching in terms of different variables. Firat University Journal of Social Sciences, 20(2), 12 1-135.

Lin, C. C. (1997). Effects of goal structure on chinese elementary school students' goal orientation, achievement, intrinsic motivatıon, and beliefs about success/fanlure A dissertation in educatıonal psychology. Ph.D Thesis. Texas Tech University.

Martin-Krumm, C. P., Sarrazin, P. G., Peterson, C., \& Famose, J. (2003). Explanatory style and resilience after sports failure. Personality and Individual Differences, 35(7), 1685-1695.Available at: https://doi.org/10.1016/s0191-8869(02)00390-2.

Menderes, Ç. H. (2009). Examining university students' achievement goal orientation according to their stress-coping styles, affective status and academic achievement. Unpublished Master's Thesis, Gazi University Institute of Educational Sciences, Department of Educational Sciences.

Midgley, C., Kaplan, A., Middleton, M., Maehr, M. L., Urdan, T., Anderman, L. H., . . Roeser, R. (1998). The development and validation of scales assessing students' achievement goal orientations. Contemporary Educational Psychology, 23(2), 113-131.Available at: https://doi.org/10.1006/ceps.1998.0965.

Pintrich, P. R. (2000). Multiple goals, multiple pathways: The role of goal orientation in learning and achievement. Journal of Educational Psychology, 92(3), 544-555.Available at: https://doi.org/10.1037/0022-0663.92.3.544.

Roebken, H. (2007). Multıple goals, satısfaction, and achievement in Unıversity Undergraduate Education: A student experience in the research university (SERU) project research paper. Research \& Occasional Paper Series: CSHE. 2.07. Center for Studies in High er Education. California.

Roeser, R., Midgley, C., \& Urdan, T. (1996). Perceptions of the school psychological environment and early adolescents' psychological and behavioral functioning in school: The mediating role of goals and belonging. Journal of Educational Psychology, 88(3), 408422.Available at: https://doi.org/10.1037/0022-0663.88.3.408.

Toğluk, E. (2009). Achievement trends of nursing students. Unpublished Master's Thesis, Istanbul University, Institute of Health Sciences, Istanbul.

Watson, D., Clarck, L. A., \& Tellegen, A. (1988). Development and validation of brief measure of pozitive and negative affect: The PANAS scales. Journal of Personaliy and Social Psychology, 54(6), 1063-1070.Available at: https://doi.org/10.1037/0022-3514.54.6.1063.

Weiner, B. (1990). History of motivational research in education. Journal of Educational Psychology, 82(4), 616-622.Available at: https://doi.org/10.1037/0022-0663.82.4.616.

Weiss, H. M., \& Cropanzano, R. (1996). Affective Events Theory: A theoretical discussion of the structure, causes and consequences of affective experiences at work. In B. M. Staw \& L. L. Cummings (Eds.), Research in organizational behavior: An annual series of analytical essays and critical reviews (Vol. 18, pp. 1-74).

Yalnız, A. (2014). Academic self-efficacy: The predictive role of positive and negative affections. Journal of Education and Training Research, $3(2), 95-101$.

Zweig, D., \& Webster, J. (2004). Validation of a multidimensional measure of goal orientation. Canadian Journal of Behavioural Science, 36(3), $232-243$. 